\title{
Optimization of a culture medium for increased mevinolin production by Aspergillus terreus strain
}

\author{
Atalla, M. M., Hamed, E. R. ${ }^{*}$ and El-Shami, A. R. \\ Chemistry of Natural and Microbial Products Dept. \\ NRC, Dokki, Cairo, Egypt. \\ E-mail:erhamed@yahoo.com
}

Received 20 November 2007; received in revised form 2 July 2008; accepted 2 July 2008

\begin{abstract}
Fungi are important sources for the production of some pharmaceutical compounds. e.g. lovastatin, mevinolin and monacolin K. These are competitive inhibitors of 3-hydroxy-3-methyl glutaryl coenzyme A reductase, the rate limiting enzyme of cholesterol synthesis pathway. Four fungal strains of Aspergillus terreus and one Penicillium patulum were tested for their potential to produce mevinolin. The fungal strains were cultivated in four different semi-synthetic media to select a fermentation medium and a fungal strain that has the ability to secret mevinolin in high yield. The fermentation followed by TLC screening. Positive results were evaluated by confirmatory HPLC. A. terreus J9 was the best strain for producing mevinolin with a level of $148.66 \mathrm{mg} / \mathrm{L}$ of Dox-rice medium. Cultivation a $7.5 \mathrm{~L}$ in fermenter, $A$. terreus $\mathrm{J} 9$ produced $932.15 \mathrm{mg} / \mathrm{L}$ after $96 \mathrm{~h}$ using Dox-rice medium at $6.5 \mathrm{pH}$. Rise in acidity or alkalinity decrease mevinolin producing ability. Ammonium sulphate in the medium as sulphur and nitrogen sources influenced greatly mevinolin production as well as incubation period. Maximum production was obtained after $36 \mathrm{~h}$ incubation. The maximum value of the mevinolin concentratiom (1761.6 mg/L) was attained at 400rpm after $60 \mathrm{~h}$ fermentation at $28{ }^{\circ} \mathrm{C}$. The optimized medium resulted in a significant increase of mevinolin cocentration, as compared with that obtained by the fermentation of many other $A$. terreus species.
\end{abstract}

Keywords: Aspergillus terreus, Lovastatin, Mevinolin, Monacolin K, secondary metabolite

\section{INTRODUCTION}

Mevinolin is the first compound of its kind to become available for treatment of hypercholesterolemia. Lovastatin acts by competitively inhibiting the enzyme (3hydroxy-3-methylglutaryl coenzyme A reductase HMGCoA) (Alberts et al., 1980 and Alberts, 1988). It is active not only in vitro to inhibit cholesterol biosynthesis but also in vivo to lower plasma choesterol level in humans and animals (Kaneko et al., 1978), thereby is effective in the therapy of hypercholesterolemia. Hyperchlesterolemia is a primary risk factor for the coronary artery disease, the major cause of death in many countries (Goldstein and Brown, 1984).

This fungal secondary metabolite is produced by Aspergillus terreus. Mevinolin was first isolated by Endo from Monascus rubber (Endo, 1979) and independently, by Alberts et al. (1980) from $A$. terreus. Since then many strains of Monascus (Negishi et al., 1986 and Chang et al., 2002) as well as a variety of other filamentous fungi including some species of Penicillium (Alberts, 1988), Hypomyces, Doratomyces, Phoma, Eupenicillium, Gymnoascus, Monascus ruber, Pleurotus and Ttrichoderma were found to produce lovastatin (Endo et al., 1986 and Samiee et al., 2003).

Behr (1998) reviewed the results obtained during the production of Monacolin $\mathrm{k}$ by solid state fermentation using Monascus purpureus strains. Fermentation process with $A$. terreus was developed to manufacture it on large scale (Buckland et al., 1989). The fungus, A. terreus, remains the organism of choice for lovastatin production. A number of studies attempting to increase lovastatin production through more efficient processes have been documented (Alberts et al., 1980 and Szakacs et al., 1998). Secondary metabolism of microorganisms is parts of their normal maturation processes (Szakacs et al., 1998). The design of fermentation media is critical, especially when the products are secondary metabolites. Although major improvements are generally ascribed to the development of superior strains, nutrient supplies also affect cellular productivity. Atalla et al. (1999) found that the commercial production of lovastatin is typically carried out using large scale of fungal fermentation. Chang et al. (2002) employed response surface methodology for production of mevinolin in submerged cultures by Monascus rubber. The optimized medium resulted in a significant increase of mevinolin yield. Lopez et al. (2003) found that production of lovastatin and microbial biomass by $A$. terrues (ATCC20542) were influenced by the type of the carbon and nitrogen sources used and the $\mathrm{C}: \mathrm{N}$ mass ratio in the medium. The behavior of the fermentation was not affected by the method of inoculation used. Li et al. (2006) studied the influencing factors, such as the kind of solvents, the acidic concentration, the initial mevinolin 
concentration, and the water content as well as temperature were investigated. Two kinds of comparative reactions, hydrolysis and alcoholysis, of mevinolin in solution were studied. This detailed study on the kinetics of mevinolin transformations is valuable and meaningful for the purification, preparation, injection manufacturing, extraction, storage, etc., of mevinolin or other similar compounds. This work provides useful information for the quality control of mevinolin and mevinolin-like drugs as well.

\section{MATERIALS AND METHODS}

\section{Fungal strains}

Aspergillus terreus isolates $\mathrm{H} 2, \mathrm{~J} 2, \mathrm{~J} 9, \mathrm{I} 2$ and Penicillium patulum was obtained from the culture collection of the NRC, Chemistry of Microbial Products, Dept. Egypt.

\section{Media and growth conditions}

\section{Culture media}

Potato dextrose agar (PDA) and Czapek Dox agar (CDA) were used for cultivation of cultures (Haung and Ling, 1973 and Difco, 1984).

\section{Fermentation media}

Four liquid media were used as fermentation media. Czapek Dox media was modified by the addition of different agriculture wastes $(150 \mathrm{~g} / \mathrm{L})$ as a sole source of carbon instead of sucrose. The modified media are: Doxrice, Dox sayfoun and Dox-deneiba in addition to Czapek Dox. $250 \mathrm{~mL}$ Erlenmeyer conical flasks each containing $50 \mathrm{~mL}$ fermentation medium were inoculated with $1 \mathrm{~mL}$ spore suspension then incubated on a rotatory incubator shaken at $180 \mathrm{rpm}$ for 1 week at $28-30^{\circ} \mathrm{C}$.

The results previously reported for mevinolin production (Atalla et al., 1999 and Shahaby et al., 1999) justified the investigation of laboratory large scale production of this product. This also provides knowledge of some of the essential information necessary for the fermentative production of this product on semi-industrial and industrial scale.

Fermentation was performed in a $7.5 \mathrm{~L}$ bench top fermenter (New Brunswick, M 1085-1003) containing $4.5 \mathrm{~L}$ of Dox liquid medium supplemented with $150 \mathrm{~g} / \mathrm{L}$ of ground rice as the sole carbon source. After autoclaving, the sterilized medium was inoculated with a $2 \%$ of $48 \mathrm{~h}$ old primary seed culture (Endo et al., 1979). The aeration rate was about one $\mathrm{v} / \mathrm{v} / \mathrm{m}(5 \mathrm{~L} / \mathrm{min})$ and stirring was maintained at $400 \mathrm{rpm}$ unless mentioned otherwise at 28 ${ }^{\circ} \mathrm{C}$. Samples were taken every $12 \mathrm{~h}$ for determining mevinolin content and $\mathrm{pH}$ values.

The culture filtrates were adjusted to $\mathrm{pH} 3$ and extracted three times with methanol $(\mathrm{v} / \mathrm{v})$. The aqueous layer was removed and the solvent layer was concentrated under vacuum till dryness and redisolved in methanol (Atalla et al.,1999), to obtain on the crude extract.

\section{Extraction, determination and purification of mevinolin}

Mevinolin was extracted from the cells and the culture filtrate. The required compound was extracted from the cells according to the method adopted by Moore et al. (1985) and Greenspan and Yudkovittz (1985) and modified by Atalla et al. (1999). The crude mevinolin sample in methanol was spotted on silica gel sheets 60 $\mathrm{F}_{254}$ developed in an ascending manner for few hours until the solvent front was about $16 \mathrm{~cm}$ length. Three solvent systems were used in volume ratio as follows: dichloromethane - acetone (4/1), methanol - chloroform $(10 / 90, v / v)$, and methanol - diethylether $(5 / 95, v / v)$. The latter proved the most suitable, accurate and reliable solvent system for separation and identification of mevinolin. Mevinolin spot was located by their blue fluorescence on chromatograms under short and long wave UV light in comparison with the standard.

In another method, a crude sample of mevinolin obtained from the previous extraction of the fermentation medium (filtrate and mycelium) with methanol was dried and dissolved in a minimum volume of the elute ethylacetate: methylene chloride $(4: 6, \mathrm{v} / \mathrm{v})$ and applied as a slurry to a silica gel column using a glass pipette. The fractions were collected in $3 \mathrm{~mL}$ portions with the aid of an LKB-Rac fraction collector. The fractions could be analyzed by thin layer chromatography on silica gel sheets using authentic sample as a reference and solvent system methanol/diethyl ether. The fractions were also analyzed using a UV spectrophotometer CE595 double beam digital CECIL instruments at $238 \mathrm{~nm}$. The pure mevinolin fractions were pooled, concentrated to a defined volume and their purities were assured by high pressure liquid chromatography (HPLC).

Other mevinolin properties were studied such as high resolution mass spectra were obtained on a Finnigan Mat SSQ-7000 spectrometer. The infra red spectra were obtained on the Fourier Transform infrared spectrometer (FT / IR-300E) using pellet of $\mathrm{KBr}$. Nuclear magnetic resonance were obtained on a Varian EM-390 MH2 NMR spectrophotometer. The compound was dissolved in dimethyl- $d_{6}$-sulphoxide (DMSO, $99.5 \%$ deuterium).

\section{RESULTS AND DISCUSSION}

\section{Effect of different media}

The purpose of this experiment was to study the effect of different media on mevinolin production by 4 different isolates of $A$. terreus $(12, \mathrm{~J} 2, \mathrm{~J} 9, \mathrm{H} 2)$ and $P$. patulum. These isolates were isolated locally and identified at NRC lab.

The results recorded in Table 1 showed that Dox's medium supplemented with crushed rice $(150 \mathrm{~g} / \mathrm{L})$ as a sole carbon source was the most suitable for mevinolin 
production especially by $A$. terreus $\mathrm{J} 9$ which produced (148.66 mg/L) followed by $A$. terreus 12 (102.67 mg/L).

On the other hand, the addition of sayfoun to Dox's medium, mevinolin production decreased greatly reaching $55-60 \%$ of that in Dox-rice with different fungal isolates. Dox-deneiba medium is the least suitable for mevinolin production with all fungal isolates used. The medium may contain the precursors of mevinolin biosynthesis other than the unsupplemented Dox medium. This result coincided with those obtained by Shahaby et al. (1999), Chang et al. (2002) and Samie et al. (2003) who found that production of lovastatin or mevacor in rice medium was superior to that of any other substrate. A. terreus J9 was recommended to produce mevinolin when grown on Dox-rice medium.

Table 1: Effect of different media on the production of mevinolin by fungi

\begin{tabular}{ccccc}
\hline Fungal & \multicolumn{4}{c}{ Mevinolin concentration (mg/L) } \\
\cline { 2 - 5 } Isolates & Rice & Sayfoun & Deneiba & Dox \\
\hline $\begin{array}{c}\text { A. terreus } \\
\text { I2 }\end{array}$ & 102.67 & 63.48 & 57.00 & 29.02 \\
$\begin{array}{c}\text { A. terrues } \\
\text { J2 }\end{array}$ & 80.00 & 66.22 & 57.00 & 45.65 \\
$\begin{array}{c}\text { A. terrues } \\
\text { J9 }\end{array}$ & 148.66 & 82.59 & 59.91 & 38.54 \\
$\begin{array}{c}\text { A. terrues } \\
\text { H2 }\end{array}$ & 82.59 & 48.86 & 29.15 & 11.01 \\
P. patulum & 66.22 & 41.28 & 33.36 & 27.85 \\
\hline
\end{tabular}

\section{Effect of incubation period}

Production of mevinolin during different incubation periods was studied by $A$. terreus $\mathrm{J} 9$ using Dox-rice medium and bench top fermenter $7.5 \mathrm{~L}$ capacity. Following $\mathrm{pH}$ changes along the experiment (Table 2) indicated that maximum production was obtained at $\mathrm{pH} 6.55(932.15 \mathrm{mg} / \mathrm{L})$ after $96 \mathrm{~h}$ incubation and then declined. The procedure agreed with that adopted by Chang et al. (2002). They employed surface methodology to increase mevinolin production in submerged cultures by Monascus rubber.

Table 2: Effect of different incubation periods on mevinolin production

\begin{tabular}{ccc}
\hline $\begin{array}{c}\text { Incubation period } \\
(\mathbf{h})\end{array}$ & $\begin{array}{c}\text { Concentration } \\
(\mathbf{m g} / \mathbf{L})\end{array}$ & Final $\mathbf{p H}$ \\
\hline 12 & 328.42 & 5.81 \\
24 & 278.22 & 6.43 \\
36 & 348.18 & 6.7 \\
48 & 829.15 & 7.12 \\
60 & 283.40 & 7.45 \\
72 & 785.43 & 7.14 \\
84 & 751.42 & 6.8 \\
96 & 932.15 & 6.55 \\
18 & 831.744 & 6.42 \\
120 & 791.90 & 6.21 \\
132 & 565.83 & 6.00 \\
144 & 381.86 & 6.00 \\
\hline
\end{tabular}

\section{Effect of initial pH}

The initial $\mathrm{pH}$ of the medium solution was adjusted at 6.5 , determined every $12 \mathrm{~h}$ and readjusted at 6.5 along the experiment. The maximum production $(96.22 \mathrm{mg} / \mathrm{L})$ was obtained after $36 \mathrm{~h}$ incubation (Table 3 ). At neutral $\mathrm{pH}$, mevinolin producing ability of the fungus increased as well as incubation decreased. It was also observed that decrease or increase in $\mathrm{pH}$ of the fermentation solution was accompanied by decrease in production. The results agreed with those of Alberts et al. (1980) and Kysilka (1993) who adjusted the $\mathrm{pH}$ of the fermentation medium at 7.4 to produce mevinolin by $A$. terreus.

Table 3: Effect of constant $\mathrm{pH}$ value on mevinolin production by fungi

\begin{tabular}{ccc}
\hline $\begin{array}{c}\text { Incubation period } \\
\text { (h) }\end{array}$ & $\mathbf{p H}$ & $\begin{array}{c}\text { Concentration } \\
\text { (mg/L) }\end{array}$ \\
\hline 12 & 6.48 & 4.22 \\
24 & 6.47 & 34.33 \\
36 & 6.62 & 96.52 \\
48 & 6.09 & 68.34 \\
60 & 6.1 & 66.23 \\
72 & 6.82 & 65.75 \\
84 & 7.15 & 54.47 \\
\hline
\end{tabular}

Effect of some nitrogen and sulpher sources on mevinolin production

In order to determine the importance of nitrogen and sulphur compounds in the fermentation medium on mevinolin production. The addition of ammonium sulphate (3 $\mathrm{g} / \mathrm{L})$ to the medium, $\mathrm{pH}$ adjusted at 6.5 increased the production (105 $\mathrm{mg} / \mathrm{L})$ after $36 \mathrm{~h}$ incubation under the optimized conditions (Table 4). The results illustrated the importance of sulphate and nitrogenous compounds for the fungus. This was in accordance with Lopez et al. (2003) results, they found that production of lovastatin and microbial biomass by $A$. terreus ATCC 20542 was influenced by the type of the carbon and nitrogen sources used and the $\mathrm{C} / \mathrm{N}$ mass ratio in the medium.

Table 4: Effect of ammonium sulphate on mevinolin production

\begin{tabular}{ccc}
\hline $\begin{array}{c}\text { Incubation period } \\
(\mathbf{h})\end{array}$ & $\mathbf{p H}$ & Concentration (mg/L) \\
\hline 12 & 6.5 & 26.88 \\
24 & 7.22 & 35.95 \\
36 & 6.5 & 105.26 \\
48 & 4.6 & 78.7 \\
60 & 5.25 & 65.1 \\
72 & 4.5 & 35.95 \\
\hline
\end{tabular}

\section{Effect of aeration level on growth and production:}

The effect of agitation speed on growth and consequently production was studied during fermentation experiments using different agitation speeds (200, 400 and $600 \mathrm{rpm})$. The aforementioned conditions were adopted also foam control. Results (Table 5) showed that $400 \mathrm{rpm}$ was the 
most suitable speed to obtain maximum production $(1761.6 \mathrm{mg} / \mathrm{L})$ after $60 \mathrm{~h}$ incubation at $28-30{ }^{\circ} \mathrm{C}$. The decrease in rpm to 200 round prolonged incubation time to $96 \mathrm{~h}$ to obtain maximum production $932 \mathrm{mg} / \mathrm{L}$ ). On the other hand, increase of rpm to 600 round decreased production to $1165.43 \mathrm{mg} / \mathrm{L}$ after $60 \mathrm{~h}$, this because high agitation speed produced fine mycelial fragments which take some time to grow to the suitable form for production. These attempts to grow and increase lovastatin production previously tried by other workers such as Szakacs et al (1998) and Atalla et al. (1999).

Table 5: Effect of the different agitation speed during fermentation

\begin{tabular}{cccc}
\hline \multirow{2}{*}{$\begin{array}{c}\text { Incubation } \\
\text { period }(\mathbf{h})\end{array}$} & \multicolumn{3}{c}{ Concentration (mg/L) } \\
\cline { 2 - 4 } & $\mathbf{2 0 0} \mathbf{~ r p m}$ & $\mathbf{4 0 0} \mathbf{~ r p m}$ & $\mathbf{6 0 0} \mathbf{~ p m}$ \\
\hline 12 & 328.42 & 362.4 & 347.77 \\
24 & 278.22 & 906.4 & 410.52 \\
36 & 384.18 & 1269.6 & 480.22 \\
48 & 829.15 & 1398.4 & 1036.43 \\
60 & 783.40 & 1761.6 & 1165.18 \\
72 & 785.43 & 1127.8 & 981.75 \\
84 & 751.42 & 906.4 & 939.27 \\
96 & 932.15 & 258.4 & 354.25 \\
\hline
\end{tabular}

Effect of fermentation temperature on growth and production

The optimum temperature for fermentation process was studied during fermentation experiments using Dox-rice medium and incubation for different periods of time at temperatures range $\left(28-32{ }^{\circ} \mathrm{C}\right)$ under the optimized conditions. Results (Table 6) showed that fermentation for $60 \mathrm{~h}$ at $28^{\circ} \mathrm{C}$ was the optimal condition for mevinolin production $(1761.6 \mathrm{mg} / \mathrm{L})$. Fluctuation in temperature more or less reflected badly on fermentation production. This confirms that the design of fermentation medium is critical; especially the products are secondary metabolites (Atalla et al., 1999).

Table 6: Effect of the different temperature on mevinolin production

\begin{tabular}{ccccc}
\hline Incubation & \multicolumn{4}{c}{ Concentration $\mathbf{( m g / L )}$} \\
\cline { 2 - 5 } period (h) & $\mathbf{2 6}{ }^{\circ} \mathbf{C}$ & $\mathbf{2 8}{ }^{\circ} \mathbf{C}$ & $\mathbf{3 0}^{\circ} \mathbf{C}$ & $\mathbf{3 2}^{\circ} \mathbf{C}$ \\
\hline 12 & 229.89 & 362.4 & 356.16 & 278.21 \\
24 & 194.22 & 906.4 & 815.76 & 328.41 \\
36 & 268.92 & 1269.6 & 1369.56 & 384.17 \\
48 & 580.4 & 1398.4 & 1358.56 & 829.14 \\
60 & 549.8 & 1761.6 & 1585.44 & 832.18 \\
72 & 652.5 & 1127.8 & 1015.02 & 785.42 \\
84 & 525.99 & 906.4 & 815.76 & 751.41 \\
96 & 311.74 & 258.4 & 335.92 & 383.4 \\
\hline
\end{tabular}

\section{CONCLUSIONS}

It can be concluded that, Aspergillus terreus J9 was the most active strain for mevinolin production when grown on rice straw medium.

The maximum production was obtained after $36 \mathrm{~h}$ incubation, $400 \mathrm{rpm}$ after $60 \mathrm{~h}$ fermentation at $28^{\circ} \mathrm{C}$.

\section{REFERENCES}

Alberts, A. W. (1988). Discovery, biochemstery and biology of lovastatin. American Journal of Cardiology $62,10-5 \mathrm{~J}$.

Alberts, A. W., Chen, J., Kuron, G., Hunt, V., Huff, F., Hoffman, C., Rothrock, J., Lopez, M., Joshua, H., Harris, E., Pachett, A., Monaghan, R., Currie, S., Stapley, E., Albers-Schonberg, G., Hensen, O., Hirschfeld, J., Hoogsteen, K., Liesch, J. and Springer, J. (1980). Mevinolin: A highly potent competitive inhibitor of hydroxymethyl-glutarylcoenzyme A reductase and a cholestrol-lowering agent. Proceedings of the National Academy of Sciences of the United States of America 77, 39573961.

Atalla, M.M., Shahaby, A.F., Eman R. Hamed and Zahra, M.K. (1999). Optimization of fermentation conditions for production of hypocholesterolaemic agent mevinolin by Penicillium patulum. Egyptian Journal of Applied Science 14 (3), 102-114.

Buckland, B., Gbewonyo, K. and Kaplan, I. (1989). Production of Lovastatin, an inhibitor of cholesterol accumulation in human. Novel microbial products for medicine and Agriculture. New York, Elsevier, 161169.

Chang, Y., Huang, J., Lee, C., Shih, I. and Tzeng, Y. (2002). Use of response surface methodology to optimize culture medium for production of lovastatin by Monascus rubber. Enzyme and Microbial Technology 30, 889-894.

Difco, M. (1984). Dehydrated Culture Media and Reagent for Microbiology. 10th Ed., Difco laboratories, Detroit Michigan, USA. 689-690.

Endo, A. (1979). Monacolin K, a new hypocholestrolaemic agent produced by a Monascus species. J. Antibiot. 32, 852-854.

Endo, A., Hasmi, K., Yamada, A., Shimoda, R. and Hiroshi, T. (1986). The synthesis of compactin (ML236B) and monacolin $\mathrm{K}$ in fungi. Journal of Antibiotics 39,1609-1616.

FDA, Doctor's Guide Publishing Limited (2004). Merck Co. Inc.

Goldestein, L. and Brown, S. (1984). Progress in understanding the LDL receptor and HMG-CoA reductase, two membrane proteins that regulate the plasma cholesterol. Journal of Lipid Research 25, 1450-1461.

Greenspan, M. D. and Yudkovitz, J. B. (1985). Mevinolinic acid biosynthesis by Aspergillus terreus and its relationship to fatty acid biosynthesis. Journal of Bacteriology 16(2), 704-707.

Huang, J. C. and Ling, K. H. (1973). Isolation and identification of a toxic hydrophilic metabolite from the 
culture broth of Penicillium sp. 171. Journal of the Formosan Medical Associaton 72, 649-657.

Kaneko, I., Hazame, Shimada, Y. and Endo, A. (1978). Inhibitory effects on lipid metabolism in cultured cells of ML-236B, a potent inhibitor of 3-hydroxy-3-methylglutaryl-coenzyme A reductase. European Journal of Biochemistry 87, 317-321.

Kysilka, R. (1993). Determination of lovastatin (mevinolin) and mevinolinic acid in fermentation liquids. Journal of Chromatography 630, 415-417.

Li, Y., Liu, H., Zhang, F., Wang, Z. and Hu, Z. (2006). Identification and kinetics study on the transformation of mevinolin in acidic alcohol solution by highperformance liquid chromatography with photodiode array detector or mass spectrometry. Chemical Research in Chinese University 22(4), 500-504.

Lopez, J., Scanchez, J., Fernandez, J., Fernandez, F., Grima, E. and Chisti, Y. (2003). Production of lovastatin by Aspergillus terreus: effects of the C:N ratio and the principal nutrients on growth and metabolite production. Enzyme and Microbial Technology 33, 270-277.

Moore, R. N., Bigam, G., Chan, J. K., Hogg, A. M., Nakashima, T. T. and Vederas, J. C. (1985). Biosynthesis of the hypercholesterolaemic agent mevinolin by Aspergillus terreus: Determination of the origin of carbon hydrogen and oxygen atoms by $\mathrm{C}^{13}$ NMR and mass spectrometry. Journal of the American Chemical Society 107(12), 3694-3701.

Negishi, S., Haung, Z. C., Hasumi, K., Murakawa, S. and Endo, A. (1986). Productivity of monacolin K (mevinolin) in the genus Monascus Hakko-KogakuKaishi., 64(6), 509-512.

Samiee, M, Moazami, N, Haghighi, S., Mohseni, F., Mirdamadi, S. and Bakhtiari, M. (2003). Screening of lovastatin production by filamentous fungi. Iranian Biomedical Journal 7(1), 29-33.

Shahaby, A. F., Atalla, M. M., Eman R. Hamed and Zahra, M. K. (1999). Screening, isolation and identification of a toxic hydrophilic metabolite mevinolin from the cultures of fungi. Egypt. J. Appl. Sci 14 (3), 87-101.

Szakacs, G., Morovjan, G. and Tengrdy, P. (1998). Production of Lovastatin by a wild strain of Aspergillus terreus. Biotechnology Letters 20(4), 411415.

Winfried, B. (1998). Dietetic and Pharmaceutical Raw Materials. Monascus fermentate: A new dietetic raw material. Net information. info@behrbonn.com. 